\title{
International Trade and Income Inequality*
}

\author{
Taiji Furusawa ${ }^{\dagger}$ \\ Hitotsubashi University \\ Hideo Konishi ${ }^{\ddagger}$ \\ Boston College
}

August 28, 2013

\begin{abstract}
We propose a theory that explains why international trade can widen a wage gap between top income-earners and others. In the basic model, we consider two symmetric countries in which individuals with different abilities work either as knowledge workers, who develop products produced in a differentiated-good sector, or as production workers, who engage in actual production processes. In equilibrium, ex ante symmetric firms post different wages for knowledge workers and hence attract workers with different abilities from other firms, creating the difference in quality of their products. International trade will benefit firms that produce high-quality products and harm firms that produce low-quality products. The relative wage gap between individuals with high ability and those with low ability expands as a result. Indeed, we show that international trade increases the real wages for those with lowest and highest abilities but decreases the real wages for those with intermediate abilities. We also extend the basic model to the one with asymmetric countries and show that income inequality worsens in the smaller or talent-scarce country while it lessens in the talent-abundant country as a result of international trade.

Preliminary and incomplete.
\end{abstract}

${ }^{*}$ Work in progress. We are grateful to James Anderson, Pol Antras, Arnaud Costinot, Elhanan Helpman, Oleg Itskhoki, Tomoya Mori, Peter Neary, and Esteban Rossi-Hansberg for helpful comments. We also thank Laura Bonacorsi and Tran Lam Anh Duong for their research assistance.

${ }^{\dagger}$ Graduate School of Economics, Hitotsubashi University. (E-mail) furusawa@econ.hit-u.ac.jp

†DDepartment of Economics, Boston College. Email: hideo.konishi@bc.edu 


\section{Introduction}

It has been widely documented that income inequality has increased significantly in many countries, especially in the developed countries. In Britain, for example, "chief executives can expect to receive average compensation in excess of $£ 4.5 \mathrm{~m}(\$ 6.9 \mathrm{~m})$ this year. Pay at the top grew by over 300\% between 1998 and 2010. At the same time, the median British worker's real wage has been pretty stagnant. These trends mean the ratio of executive to average pay at FTSE 100 firms jumped from 47 to 120 times in 12 years." (The Economist, January 14th-20th, 2012, p. 11) It has also been documented that job polarization has occurred in many developed countries, including the United States and some European countries, such that the shares of employment in high-skilled occupations and low-skilled occupations grow while that of middle-wage occupation declines (Acemoglu and Autor, 2011).

Technological changes and globalization are often argued to be the causes of the job polarization and expansion of income inequality. Machines have replaced middle-skilled workers who engage in routine tasks. Offshoring routine tasks to low-wage countries reduces demands for middle-skilled workers in high-wage developed countries. Offshoring is unambiguously an important aspect of globalization. But we argue here that international trade in goods, which is more fundamental part of globalization, alone can cause some sort of job polarization and

expand income inequality among different skill groups of workers. In particular, we relate the recent trend of market concentration in manufacture industries, i.e., the winner-take-all market trend, to the job polarization and the expansion of the income inequality. Thanks to globalization (i.e., an increase in the market size and wider information transmission), a difference in quality becomes an important source of differential profitability within industries: firms that sells high-quality products command disproportional market shares. This, in turn, gives workers who work as knowledge workers in the winning firms disproportional shares of income. Knowledge workers in such firms are winners because they are the sources of the firms' success. But that implies that the war for talent arises and large portion of the firms' operating profits go to the knowledge workers as the rents for their talents. What determines the product quality is the talent of knowledge workers such as managers and 
R\&D workers hired in firms. Firms that hire talented knowledge workers enjoy benefits from the employment, which in turn benefits such knowledge workers in the form of high wages.

To show this phenomenon, which becomes more and more important in recent years, we build a two-country variant of Lucas's (1978) model in which ex ante symmetric firms in the representative differentiated-good (manufacture) sector hire knowledge workers with different abilities, thereby producing products with different qualities. In equilibrium, knowledge workers are assortatively allocated in different firms: firms that hire a group of highlytalented knowledge workers produce high-quality products, while those hire mediocre knowledge workers produce relatively low-quality products. Firms also hire production workers to produce their products. We assume that workers are homogeneous in their productivities when hired as production workers despite the difference in their abilities. The wage gap may arise between knowledge workers and production workers even within a firm; the wage gap within a firm is particularly serious in profitable firms that produce high-quality products.

International trade affects firms' profitability differently across firms. Top-tier firms that produce high-quality products are the winners of opening to trade; getting access to an additional market give them large benefits. Medium-tier and Lowest-tier firms, on the other hand, loose from opening to trade. They suffer from foreign top-tier firms' penetration into their own market. Although the medium-tier firms may sell their products to the foreign market as well as their own market, the additional export profits after the subtraction of fixed export costs are not enough to offset the loss that they incur in their domestic market. Consequently, top income earners who are best talented and work in the top-tier exporting firms benefit from opening to trade; they are the winners of globalization. On the contrary, workers in the middle-income class, who (used to) work as knowledge workers in the middletier firms, are likely to suffer from opening to trade. Their nominal incomes drop because the profits for the firms in which they are working fall after trade liberalization. Although the real wages may still rise thanks to the increased varieties of products in their consumption after trade liberalization, we show that under a relatively mild condition their real wages decline by opening to trade. Indeed, workers in the middle-income class are the only losers 
from trade liberalization. Thanks to the increased varieties in consumption, the real wages for the least talented workers, who work as production workers, increase by opening to trade.

We also extend the basic model to the case of asymmetric countries. We find through numerical simulations that income inequality worsens in the smaller or talent-scarce country while it lessens in the talent-abundant country as a result of international trade.

We are not the first to theoretically predict that international trade widens wage gap across different income groups. Manasse and Turrini (2001), Yeaple (2005), Costinot and Vogel (2010), Helpman et al. (2010a), Helpman et al. (2011), Helpman et al. (2010b), and Blanchard and Willmann (2011), among others, show in their models that international trade in goods widens wage gap at least in some trading countries.

Among these studies, Manasse and Turrini (2001) and Yeaple (2005) are the closest to our paper. Manasse and Turrini (2001) employ the same basic model structure as ours; ex ante symmetric firms produce products of different qualities because they are run by entrepreneurs with different abilities. In their analysis, however, the number of firms in the differentiated good industry is fixed and it is not affected by opening to trade. As a consequence, they cannot analyze how international trade affects profitability of firms and hence the wage distribution through a change in the number of operating firms. This channel is important because the winner-take-all phenomenon is prevalent in the global markets and this reduces the number of firms in each industry, thereby reducing the jobs for workers in the middle-income class. Yeaple (2005) derives similar predictions to ours in a similar model environment. In his model, firms choose both their individual production technologies and types of workers. A distinguishing feature of his model is the complementarity between the technology and skills of labor; high productivity technology is matched with high-skilled workers. Beside the fact that the average talent of knowledge workers is the only source of firm heterogeneity in our model, our model is different from his in that we separate labor into two endogenously allocated categories: knowledge workers and production workers. This distinction is a key to our analysis of the impact of trade on income redistribution. First, we can discuss differential effects of trade on workers within firms, which is an important wage 
gap besides the wage gap within sectors and within occupations. Second and more broadly, separating knowledge workers from production workers is important to understand the effect of globalization on labor market. Knowledge can be embedded into products so that it is duplicated unboundedly with the help of capital and production workers to possibly earn a fortune in the global market. Globalization does not necessarily increase the demands for knowledge workers. It only increases the demands for talent. Knowledge created by a limited number of knowledge workers is embedded in the products and travels over the world.

Monte (2011) and Egger and Kreickemeier (2012) also extend Lucas's (1978) model to examine the impact of international trade on income distribution. Since their interest is slightly different from ours, they do not show that trade reduces the real wage of the middleincome class. We believe that our model is the simplest one to show the negative impact of trade on the middle-income class capturing the important aspect of globalization: the winner-take-all market and war for talent.

\section{The Model}

We consider a model of two countries (countries 1 and 2), one good(a differentiated good with many varieties), and one production factor (labor). The differentiated good consists of a continuum of varieties, each of which (denoted by $\omega \in \Omega$ ) is produced under monopolistic competition by a firm in a continuum pool of firms. Quality of the differentiated good, which is represented by $\alpha(\omega)$, may vary across varieties. Following Caliendo and Rossi-Hansberg (2012), we represent a representative consumer's preferences by the utility function:

$$
u=\left[\int_{\Omega} \alpha(\omega)^{\frac{1}{\sigma}} x(\omega)^{\frac{\sigma-1}{\sigma}} d \omega\right]^{\frac{\sigma}{\sigma-1}}
$$

where $x(\omega)$ denote the consumption level of a variety $\omega$ of the differentiated good and $\sigma>1$ denotes the elasticity of substitution. The higher the $\alpha(\omega)$, the higher the utility a consumer derives from the consumption of variety $\omega$.

In each country $i=1,2$, there is a continuum of workers with the mass $L_{i}$; each worker provides 1 unit of labor. Labor is the only production factor in this economy. But a worker is 
employed either as a knowledge worker in the differentiated good sector to develop a product or as a production worker to produce the differentiated goods. We choose labor provided by production workers as the numeraire. Workers are heterogeneous in their abilities that only matter when they are hired as knowledge workers. Thus, they are heterogeneous as knowledge workers, but homogenous as production workers. In the basic model, ability is measured by $a \in \mathbb{R}_{+}$, the distribution of which in country $i$ is described by the cumulative distribution function $G_{i}$ with the probability density function $g_{i}$; the mass of workers with their abilities less than or equal to $a$ is, therefore, given by $L_{i} G_{i}(a)$. In the basic model, we assume that countries 1 and 2 are symmetric: that is, $L_{1}=L_{2}=L$ and $G_{1}(a)=G_{2}(a)=$ $G(a)$ for all $a \in \mathbb{R}_{+}$.

The differentiated good market is under the monopolistic competition with free entry and exit. To enter the market, firms need to develop the product by hiring $l^{s}$ knowledge workers, which serves as entry costs. The average ability level of these workers determines the quality of the product; we simply assume that the quality of the product $\alpha(\omega)$ is equal to the average talent level of the knowledge workers employed in the firm. Production of a product itself requires only production workers; 1 unit of labor produces 1 unit of the good.

There is no friction in the labor markets, both for knowledge workers and production workers, nor does there exist information asymmetry between workers and firms on individual workers' ability levels. Since the average ability level of knowledge workers determines the product quality, firms in the differentiated good sector compete for talent. They post wages for knowledge workers, and workers apply for those positions; we assume that each firm offers a wage that equally applies to every knowledge worker within the firm regardless of the workers' abilities. ${ }^{1}$ Then each firm chooses $l^{s}$ workers from those who have applied for the firm's position.

\footnotetext{
${ }^{1}$ If we assume alternatively that a firm posts a wage profile that possibly assigns a higher wage to a worker with a higher ability, we would have another equilibrium in which a firm attracts workers with different abilities. But such equilibrium would disappear if (even a slight) complementarity between knowledge workers' abilities within the firms is introduced. Since our aim is to construct a simple and yet plausible model to show that the middle-income class suffers from the globalization, we make the assumption that each firm pays the same wage to all knowledge workers and examine the properties of the equilibrium in which knowledge workers are sorted into the firms according to their abilities.
} 
In equilibrium, matching between firms and knowledge workers must be stable. The firms post different wages for knowledge workers attracting workers with different ability levels. Workers with highest abilities are hired by the firms that post highest wages, such that workers are sorted according to their ability levels. Thanks to the competition among the firms, the entire operating profits for each firm are given as a rent to the knowledge workers. Letting $w(\omega)$ denote the knowledge worker's wage (or rent) in the firm that produces the variety $\omega$ and $\tilde{\pi}(\omega)$ denote the firm's operating profits, we therefore have

$$
w(\omega) l^{s}=\tilde{\pi}(\omega)
$$

The firms produce varieties of different quality in equilibrium. The firm distribution with respect to their product quality is determined from the ability distribution, since the average ability level of knowledge workers determines the product quality. The distribution of workers with respect to their abilities can be characterized by a density function of $\operatorname{Lg}(a)$ such that the mass of workers whose abilities are greater than or equal to $\alpha$ is given by $L[1-G(\alpha)]$. In this model with a continuum of workers, all knowledge workers in a firm will have a common ability. Therefore, letting $f(\alpha)$ denote the density of firms that produce varieties of quality $\alpha$, we have

$$
f(\alpha)=\frac{L g(\alpha)}{l^{s}}
$$

Workers who are not hired as knowledge workers will work as production workers. In equilibrium, there will be a cutoff ability level $\alpha^{*}$ such that all workers with $a \geq \alpha^{*}$ work as knowledge workers, while all workers with $a<\alpha^{*}$ work as production workers. Once $\alpha^{*}$ is given, together with (3), the distribution of operating firms is completely determined.

\section{Autarkic Equilibrium}

This section derives the autarkic equilibrium and shows that knowledge workers obtain higher wages than production workers and that knowledge workers' wages increase proportionately with their ability levels.

Thanks to the symmetry assumed in the basic model, we need only consider a country 
to derive an autarkic equilibrium. First, we use a consumer's (or worker's) demands derived from (1) to obtain a firm's production level and profits. Let $I$ denote the aggregate income of a country. Since the wage of production workers is normalized to 1, each firm optimally selects the price of $p(\alpha)=\sigma /(\sigma-1)$, the constant mark-up price over the marginal cost of 1 , regardless of its product quality $\alpha$. Consequently, the firm that produces a variety of quality $\alpha$ sells

$$
x(\alpha)=\frac{\alpha p(\alpha)^{-\sigma}}{\int_{\alpha^{*}}^{\infty} \alpha p\left(\alpha^{\prime}\right)^{1-\sigma} f\left(\alpha^{\prime}\right) d \alpha^{\prime}} I=\frac{\alpha}{\int_{\alpha^{*}}^{\infty} \alpha^{\prime} f\left(\alpha^{\prime}\right) d \alpha^{\prime}} \frac{(\sigma-1) I}{\sigma}
$$

units of the good. The firm's production level is higher, the higher is the quality of its product and the smaller is the quality index, $\int_{\alpha^{*}}^{\infty} \alpha^{\prime} f\left(\alpha^{\prime}\right) d \alpha^{\prime}$. The operating profits for the firm that produces a product with quality $\alpha$ are given by

$$
\tilde{\pi}(\alpha)=\frac{\alpha I}{\sigma \int_{\alpha^{*}}^{\infty} \alpha^{\prime} f\left(\alpha^{\prime}\right) d \alpha^{\prime}} .
$$

Henceforth, we identify a firm by the quality of its product rather than $\omega \in \Omega$, since all firms that produce the good of the same quality have the same characteristics.

Letting $w(\alpha)$ denote the wage for a knowledge worker with ability $a=\alpha$, who is hired by the firm that produces the product of quality $\alpha$ (with slight abuse of notation), we can write the profits for the firm as

$$
\pi(\alpha)=\tilde{\pi}(\alpha)-w(\alpha) l^{s}
$$

If $\pi(\alpha)$ is greater than 0 for some firm with $\alpha$, an entrant would post a slightly higher wage than $w(\alpha)$ and get all the knowledge workers from such a firm to profitably operate. Therefore, $\pi(\alpha)=0$ in equilibrium, so that the knowledge workers' wage schedule is given by $w(\alpha)=\tilde{\pi}(\alpha) / l^{s}$ as $(2)$ indicates.

The equilibrium is characterized by the two conditions: the free-entry (FE) condition and the labor-market clearing (LM) condition. The free-entry condition expresses that the cutoff firms with $\alpha^{*}$ earns zero profits. The knowledge workers in the cutoff firms earn the wage of 1, i.e., $w\left(\alpha^{*}\right)=1$, in equilibrium, since if $w\left(\alpha^{*}\right)>1$ profitable entry by a firm that posts the wage of 1 , for example, would occur. Thus, the free-entry condition can be written 
as

$$
\frac{\alpha^{*} I}{\sigma \int_{\alpha^{*}}^{\infty} \alpha f(\alpha) d \alpha}=l^{s} .
$$

The labor-market clearing condition, on the other hand, expresses that total labor demands, the sum of demands for knowledge workers and those for production workers, must equal the labor supply $L$. Total demands for knowledge workers are given by $l^{s} \int_{\alpha^{*}}^{\infty} f(\alpha) d \alpha$. Total demands for production workers equal $(\sigma-1) I / \sigma$ as we can easily obtain from (4). Thus, the labor-market clearing condition can be written as

$$
l^{s} \int_{\alpha^{*}}^{\infty} f(\alpha) d \alpha+\frac{\sigma-1}{\sigma} I=L .
$$

Figure 1 depicts the relationships between $\alpha^{*}$ and $I$ that express the free-entry and labormarket clearing conditions. The free-entry condition can be expressed by a negatively-sloped schedule $F E$, since the left-hand side of (6) increases with both $\alpha^{*}$ and $I$. The labor-market clearing condition, on the other hand, can be expressed by a positively-sloped schedule $L M$, since the left-hand side of (7) decreases with $\alpha^{*}$ but increases with $I$. The intersection of these two schedules gives us the equilibrium values of $\alpha^{*}$ and $I$, which we call $\alpha_{A}^{*}$ and $I_{A}$.

Once the equilibrium threshold $\alpha_{A}^{*}$ is determined, the equilibrium wage schedule is readily obtained. As Figure 2 shows, wages are flat at 1 for all workers with their ability levels smaller than $\alpha_{A}^{*}$. Their wages are 1 because they work as production workers. Those who have abilities greater than $\alpha_{A}^{*}$, on the other hand, work as knowledge workers. Their wages are the rents for their abilities and are greater than 1 except for the knowledge workers whose ability levels are exactly equal to $\alpha_{A}^{*}$. As we can see from (5), the ratio of wages for knowledge workers with any two different levels of abilities is equal to the ratio of their abilities itself:

$$
\frac{w_{A}(\alpha)}{w_{A}\left(\alpha_{A}^{*}\right)}=\frac{\tilde{\pi}(\alpha)}{\tilde{\pi}\left(\alpha_{A}^{*}\right)}=\frac{\alpha}{\alpha_{A}^{*}},
$$

where we can compare the wage for a knowledge worker with ability $a=\alpha$ with that for a knowledge worker with ability $a=\alpha_{A}^{*}$. Since $w_{A}\left(\alpha_{A}^{*}\right)=1$, we can write the wage of a worker as a function of her ability:

$$
w_{A}(a)=\left\{\begin{array}{cll}
1 & \text { if } & 0 \leq a<\alpha_{A}^{*} \\
a / \alpha_{a}^{*} & \text { if } \quad & a \geq \alpha_{A}^{*} .
\end{array}\right.
$$


The equilibrium utility for a worker, which can also be considered as the real wage, can be readily derived. It is easy to infer from (4) that the worker with ability a consumes

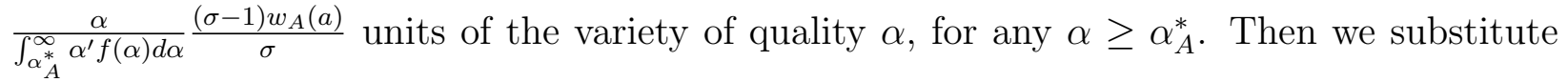
them into (1) to obtain the worker's indirect utility in the autarkic equilibrium:

$$
u_{A}(a)=\frac{(\sigma-1) w_{A}(a)}{\sigma\left[\int_{\alpha_{A}^{*}}^{\infty} \alpha f(\alpha) d \alpha\right]^{\frac{1}{1-\sigma}}}
$$

Not surprisingly, the equilibrium utility for an individual depends on both her wage and the quality index of the market.

\section{Trade Equilibrium}

Let us turn to the analysis of the impact of international trade between the two symmetric countries on the firms' activities and the wage schedule in individual countries. We suppose that firms need to incur $f_{X}$ units of labor as the fixed cost of exporting. Exporting firms also incur iceberg trade cost such that they need to ship $\tau(>1)$ units of the good to supply 1 unit in the foreign market.

We consider the realistic case in which only a fraction of the firms export their products. Let $\alpha^{X}$ denote the threshold quality such that the products are exported (as well as supplied domestically) if and only if their individual qualities are higher than or equal to $\alpha^{X}$. It is easy to see that the operating profits from the domestic sales and foreign sales are given by

$$
\begin{aligned}
\tilde{\pi}_{d}(\alpha) & =\frac{\alpha I}{\sigma\left[\int_{\alpha^{*}}^{\infty} \alpha^{\prime} f(\alpha) d \alpha+\tau^{1-\sigma} \int_{\alpha^{X}}^{\infty} \alpha^{\prime} f\left(\alpha^{\prime}\right) d \alpha^{\prime}\right]} \\
\tilde{\pi}_{X}(\alpha) & =\frac{\alpha \tau^{1-\sigma} I}{\sigma\left[\int_{\alpha^{*}}^{\infty} \alpha^{\prime} f\left(\alpha^{\prime}\right) d \alpha^{\prime}+\tau^{1-\sigma} \int_{\alpha^{X}}^{\infty} \alpha^{\prime} f\left(\alpha^{\prime}\right) d \alpha^{\prime}\right]}
\end{aligned}
$$

respectively. Then, the profits for the firm that produces a product of quality $\alpha$ are equal to

$$
\pi(\alpha)= \begin{cases}\tilde{\pi}_{d}(\alpha)-w(\alpha) l^{s} & \text { if } \alpha^{*} \leq \alpha<\alpha^{X} \\ \tilde{\pi}_{d}(\alpha)+\tilde{\pi}_{X}(\alpha)-w(\alpha) l^{s}-f_{X} & \text { if } \alpha \geq \alpha^{X} .\end{cases}
$$

Since the values of the quality index are the same between the two countries due to the symmetry, it is easy to compare the operating profits from exporting and those from domestic 
sale. In particular, we compare the operating export profits for the export-cutoff firm with $\alpha^{X}$, i.e., $\tilde{\pi}_{X}\left(\alpha^{X}\right)=f_{X}$, and the profits for the entry-cutoff firm with $\alpha^{*}$, i.e., $\tilde{\pi}_{d}\left(\alpha^{*}\right)$. Then, it follows from (9) and (10) that the relationship between $\alpha^{X}$ and $\alpha^{*}$ can be expressed by the function:

$$
\alpha^{X}\left(\alpha^{*}\right)=\frac{\tau^{\sigma-1} f_{X}}{l^{s}} \alpha^{*}
$$

We assume that $\tau^{\sigma-1} f_{X}>l^{s}$ so that only a fraction of the firms export their products.

The free-entry condition and the labor-market clearing condition can be written as

$$
\begin{gathered}
\frac{\alpha^{*} I}{\sigma\left[\int_{\alpha^{*}}^{\infty} \alpha f(\alpha) d \alpha+\tau^{1-\sigma} \int_{\alpha^{X}\left(\alpha^{*}\right)}^{\infty} \alpha f(\alpha) d \alpha\right]}=l^{s}, \\
l^{s} \int_{\alpha^{*}}^{\infty} f(\alpha) d \alpha+f_{X} \int_{\alpha^{X}\left(\alpha^{*}\right)}^{\infty} f(\alpha) d \alpha+\frac{\sigma-1}{\sigma} I=L,
\end{gathered}
$$

respectively.

By comparing the free-entry condition (12) with the autarkic counterpart (6), we find that the FE schedule shifts up as Figure 3 indicates. International trade intensifies the domestic competition. In order for the same threshold producer to be break-even, the total income must increase. Similarly, by comparing (13) with (7), we see that the LM schedule shifts down. The labor market becomes tighter because trade creates additional demands for labor that is used for exporting. Thus, the income must decrease so that these increased demands are offset by the decreased demands for production workers. Trade equilibrium income denoted by $I_{T}$ may be greater or smaller than $I_{A}$, i.e., the impact of trade on the nominal income measured by the numeraire good is ambiguous. However, trade will unambiguously raise the threshold quality $\alpha_{T}^{*}$ (Melitz, 2003). International trade intensifies competition in individual domestic markets, which lowers the profitability of firms that only serve their individual domestic markets. In addition, the labor market becomes tighter due to the demands for labor for exporting. These two effects work as factors to increase the bar to enter the industry.

Proposition 1 (Melitz, 2003) International trade raises the threshold quality of the differentiated good $\alpha_{A}^{*}\left(<\alpha_{T}^{*}\right.$ and hence raises the average quality of the good. 
The main focus of the paper is to examine the impact of trade on the wage schedule. It follows from (11) and $\tilde{\pi}_{X}(\alpha) / \tilde{\pi}_{X}\left(\alpha^{X}\right)=\alpha / \alpha^{X}$ together with $\tilde{\pi}_{X}\left(\alpha^{X}\right)=f_{X}$ that the equilibrium wage schedule is described by a piecewise linear function:

$$
w_{T}(\alpha)=\left\{\begin{array}{ccc}
1 & \text { for } & \alpha \in\left[0, \alpha_{T}^{*}\right) \\
\frac{\alpha}{\alpha_{T}^{*}} & \text { for } & \alpha \in\left[\alpha_{T}^{*}, \alpha^{X}\right) \\
\frac{\alpha}{\alpha_{T}^{*}}+\frac{\left(\alpha-\alpha^{X}\right) f_{X}}{l^{s} \alpha^{X}} & \text { for } & \alpha \in\left[\alpha^{X}, \infty\right) .
\end{array}\right.
$$

Figure 4 shows how wage schedule changes as a result of opening to trade. The wage schedule in trade equilibrium shows that there are more production workers, who earn the wage of 1 , than those before opening to trade since trade decreases the mass of firms. Note in particular that workers whose ability $a$ is between $\alpha_{A}^{*}$ and $\alpha_{T}^{*}$ used to work as knowledge workers but now work as production workers after opening to trade. In trade equilibrium, workers whose ability is between $\alpha_{T}^{*}$ and $\alpha^{X}$ work as knowledge workers in the firms that serve only their own domestic market. Their wages are lower in trade equilibrium than in autarky because their firms suffer from increased competition in their domestic market. Workers whose abilities are greater than $\alpha^{X}$ are the knowledge workers who work in firms that export their products. Profits for a firm that barely meets the criterion for exporting are smaller than those in autarky. This is because profits from exporting after paying the fixed costs of exporting are not sufficient to offset the losses in the domestic sales caused by the import penetration. Wages for knowledge workers who work in such firms also decline as a result of opening to trade. However, the wages for knowledge workers whose abilities are sufficiently high benefit from trade, since trade disproportionately increases the profits for the firms that hire such knowledge workers. Trade increases nominal wages (measured by labor provided by the production workers) only for those who are highly talented. Extraordinary talent pays disproportionately in the world of globalization. Such talents are embodied in products and travel over the world.

Proposition 2 International trade raises the nominal income (measured by labor provided by the production workers) only for those who are most talented.

What is the impact of trade on real wages? Similarly to (8), the worker's indirect utility 
in the trade equilibrium can be written as

$$
u_{T}(a)=\frac{(\sigma-1) w_{T}(a)}{\sigma\left[\int_{\alpha_{T}^{*}}^{\infty} \alpha f(\alpha) d \alpha+\int_{\alpha^{X}}^{\infty} \alpha f(\alpha) d \alpha\right]^{\frac{1}{1-\sigma}}} .
$$

It is easy to see that those who work as production workers both before and after opening to trade benefit from trade. Their real wages increase because the price index falls due to the increased varieties in consumption while the nominal wages are unaffected. It is even more obvious that most talented workers whose nominal incomes increase after opening to trade also benefit from trade. What about the impact on the middle-income class? To derive a clear-cut answer to this question, we assume now that the ability is distributed according to the Pareto distribution with its cumulative distribution function $G(a)=1-\left(a_{0} / a\right)^{k}$, where $a_{0}>0$ and $k>1$. Then, it can be shown that under the mild condition that $\sigma>2$, international trade decreases the real wages for the middle-income class as Figure 5 shows.

Proposition 3 Suppose that there are two symmetric countries in which workers' ability distribution follows a Pareto distribution. Then, the lowest income earners who work as production workers as well as the highest income earners who work as knowledge workers are better off by international trade. Those who belong to the middle-income class, however, experience a decrease in real wages by opening to trade: there is a range of workers' ability such that the real wages of workers whose abilities are within this range fall as a result of opening to trade if and only if $\sigma>2$ holds. All knowledge workers who work in firms that only serve their individual domestic markets in trade equilibrium belong to such middle-income class.

An individual that belongs to the middle-income class (e.g., knowledge workers with $a \in$ $\left.\left[\alpha_{T}^{*}, \alpha^{X}\right]\right)$ benefits from trade as a consumer due to a decrease in the price index, but loses as a residual claimer of the firm since a decrease in the price index leads to a decreases in the firm's operating profits. The latter effects outweighs the former if and only if $\sigma>2$, i.e., the elasticity of substitution is large enough that the latter competition-enhancing effect is dominant. 
Having derived the impacts of trade on individual workers' real wages, we now turn to the impact on overall social welfare of each country. We use two measures of social welfare to evaluate the effect of international trade: the utilitarian social welfare and the Lorenz domination. If the ability is distributed according to a Pareto distribution, we also have unambiguous results regarding the impact of trade on social welfare in both measures.

The following proposition, the proof of which is relegated to the Appendix, shows that trade unambiguously increases a simple aggregation of individuals' utilities.

Proposition 4 Suppose that there are two symmetric countries in which workers' ability distribution follows a Pareto distribution. Then, international trade unambiguously improves utilitarian social welfare for individual countries.

The other measure of social welfare is the Lorenz domination, which is a measure to evaluate the equality of income distribution. We define the Lorenz function by

$$
\mathcal{L}(a)=\frac{\int_{0}^{a} w\left(a^{\prime}\right) d G\left(a^{\prime}\right)}{\int_{0}^{\infty} w\left(a^{\prime}\right) d G\left(a^{\prime}\right)},
$$

the fraction of total income earned by those who have the ability $a$ or less. We say that the income distribution characterized by the Lorenz function $\mathcal{L}_{\mathcal{A}}$ is Lorenz-dominated by the one characterized by $\mathcal{L}_{\mathcal{B}}$, if $\mathcal{L}_{A}(a) \leq \mathcal{L}_{B}(a)$ for any $a$ with strict inequality for some $a$.

Proposition 5 Suppose that there are two symmetric countries in which workers' ability distribution follows a Pareto distribution. Then, the income distribution under international trade is Lorenz-dominated by the one under autarky.

The Appendix shows the proof of Proposition 5.

Propositions 4 and 5 give us clear and important message to us about the impact of international trade on income distribution. International trade benefits a country as a whole, but increases income inequality within the country. 


\section{$5 \quad$ Asymmetric Countries}

In this section, we extend the basic model to the one in which countries are asymmetric in population or ability distribution. We will show numerically that the impact of trade on income inequality is severer in the smaller country than the larger country and that income inequality worsens in the talent-scarce country as in the case of symmetric countries but it lessens in the talent-abundant country as a result of international trade.

We examine the two cases (i) that country 1 is larger than country 2 , i.e., $L_{1}>L_{2}$ and (ii) that country 1 has relatively more workers of high ability than country 2. The second case is characterized by the first-order stochastic dominance of the Pareto distributions for workers' ability. Specifically, we assume that $k_{1}<k_{2}$ so that $G_{1}(a)<G_{2}(a)$ for any $a>a_{0}$, where $G_{i}(a)=1-\left(a_{0} / a\right)^{k_{i}}$. Before we examine these two cases separately, we shall derive the equilibrium conditions, noting that the firm distribution in country $i$ is given by the density function similar to the one in (3):

$$
f_{i}(\alpha)=\frac{L_{i} g_{i}(\alpha)}{l^{s}}
$$

We choose the labor provided by the production workers in country 2 as a numeraire, so the wage rate for the production workers in country 2 equals 1 . We let $w$ denote the wage rate for the production workers in country 1.

To derive the equilibrium conditions, we first note that the total income for each country equals the total revenue for all the domestic firms. We can write the total income for country 1, for example, as

$$
I_{1}=\frac{w^{1-\sigma} \int_{\alpha_{1}^{*}}^{\infty} \alpha f_{1}(\alpha) d \alpha}{w^{1-\sigma} \int_{\alpha_{1}^{*}}^{\infty} \alpha f_{1}(\alpha) d \alpha+\tau^{1-\sigma} \int_{\alpha_{2}^{X}}^{\infty} \alpha f_{2}(\alpha) d \alpha} I_{1}+\frac{w^{1-\sigma} \tau^{1-\sigma} \int_{\alpha_{1}^{X}}^{\infty} \alpha f_{1}(\alpha) d \alpha}{\int_{\alpha_{2}^{*}}^{\infty} \alpha f_{2}(\alpha) d \alpha+w^{1-\sigma} \tau^{1-\sigma} \int_{\alpha_{1}^{X}}^{\infty} \alpha f_{1}(\alpha) d \alpha} I_{2} .
$$

Using (15), we can rewrite this equality as

$$
I_{1}=\frac{w^{1-\sigma} L_{1} \int_{\alpha_{1}^{*}}^{\infty} \alpha d G_{1}(\alpha)}{w^{1-\sigma} L_{1} \int_{\alpha_{1}^{*}}^{\infty} \alpha d G_{1}(\alpha)+\tau^{1-\sigma} L_{2} \int_{\alpha_{2}^{X}}^{\infty} \alpha d G_{2}(\alpha)} I_{1}+\frac{w^{1-\sigma} \tau^{1-\sigma} L_{1} \int_{\alpha_{1}^{X}}^{\infty} \alpha d G_{1}(\alpha)}{L_{2} \int_{\alpha_{2}^{*}}^{\infty} \alpha d G_{2}(\alpha)+w^{1-\sigma} \tau^{1-\sigma} L_{1} \int_{\alpha_{1}^{X}}^{\infty} \alpha d G_{1}(\alpha)} I_{2} .
$$

Similarly, we have

$$
I_{2}=\frac{L_{2} \int_{\alpha_{2}^{*}}^{\infty} \alpha d G_{2}(\alpha)}{L_{2} \int_{\alpha_{2}^{*}}^{\infty} \alpha d G_{2}(\alpha)+w^{1-\sigma} \tau^{1-\sigma} L_{1} \int_{\alpha_{1}^{X}}^{\infty} \alpha d G_{1}(\alpha)} I_{2}+\frac{\tau^{1-\sigma} L_{2} \int_{\alpha_{2}^{X}}^{\infty} \alpha d G_{2}(\alpha)}{w^{1-\sigma} L_{1} \int_{\alpha_{1}^{*}}^{\infty} \alpha d G_{1}(\alpha)+\tau^{1-\sigma} L_{2} \int_{\alpha_{2}^{X}}^{\infty} \alpha d G_{2}(\alpha)} I_{1},
$$


for country 2. Although they look different, it is easy to show that these two equations are equivalent and can be written as

$$
\frac{w^{1-\sigma} \tau^{1-\sigma} L_{1} \int_{\alpha_{1}^{X}}^{\infty} \alpha d G_{1}(\alpha)}{L_{2} \int_{\alpha_{2}^{*}}^{\infty} \alpha d G_{2}(\alpha)+w^{1-\sigma} \tau^{1-\sigma} L_{1} \int_{\alpha_{1}^{X}}^{\infty} \alpha d G_{1}(\alpha)} I_{2}=\frac{\tau^{1-\sigma} L_{2} \int_{\alpha_{2}^{X}}^{\infty} \alpha d G_{2}(\alpha)}{w^{1-\sigma} L_{1} \int_{\alpha_{1}^{*}}^{\infty} \alpha d G_{1}(\alpha)+\tau^{1-\sigma} L_{2} \int_{\alpha_{2}^{X}}^{\infty} \alpha d G_{2}(\alpha)} I_{1} .
$$

The left-hand side of this equation represents the total value of country 1's exports while the right-hand side represents country 2's counterpart. Thus, this equation shows that the trade should balance between the two countries, which is the first equilibrium condition of this extended model.

The second set of equilibrium conditions are the free-entry conditions for countries 1 and 2. Using (15), we can write the conditions as

$$
\begin{gathered}
\frac{w^{1-\sigma} \alpha_{1}^{*} I_{1}}{\sigma\left[w^{1-\sigma} L_{1} \int_{\alpha_{1}^{*}}^{\infty} \alpha d G_{1}(\alpha)+\tau^{1-\sigma} L_{2} \int_{\alpha_{2}^{X}}^{\infty} \alpha d G_{2}(\alpha)\right]}=w, \\
\frac{\alpha_{2}^{*} I_{2}}{\sigma\left[L_{2} \int_{\alpha_{2}^{*}}^{\infty} \alpha d G_{2}(\alpha)+w^{1-\sigma} \tau^{1-\sigma} L_{1} \int_{\alpha_{1}^{X}}^{\infty} \alpha d G_{1}(\alpha)\right]}=1 .
\end{gathered}
$$

Whereas these conditions determine the entry cutoffs for the two countries, the next two conditions determine the cutoff qualities for exporting firms:

$$
\begin{gathered}
\frac{l^{s} w^{1-\sigma} \tau^{1-\sigma} \alpha_{1}^{X} I_{2}}{\sigma\left[L_{2} \int_{\alpha_{2}^{*}}^{\infty} \alpha d G_{2}(\alpha)+w^{1-\sigma} \tau^{1-\sigma} L_{1} \int_{\alpha_{1}^{X}}^{\infty} \alpha d G_{1}(\alpha)\right]}=w f_{X}, \\
\frac{l^{s} \tau^{1-\sigma} \alpha_{2}^{X} I_{1}}{\sigma\left[w^{1-\sigma} L_{1} \int_{\alpha_{1}^{*}}^{\infty} \alpha d G_{1}(\alpha)+\tau^{1-\sigma} L_{2} \int_{\alpha_{2}^{X}}^{\infty} \alpha d G_{2}(\alpha)\right]}=f_{X},
\end{gathered}
$$

for countries 1 and 2, respectively.

The last two conditions are the labor-market clearing conditions:

$$
\begin{aligned}
L_{1} \int_{\alpha_{1}^{*}}^{\infty} d G_{1}(\alpha) & +\frac{f_{X} L_{1}}{l^{s}} \int_{\alpha_{1}^{X}}^{\infty} d G_{1}(\alpha)+\frac{w^{1-\sigma} L_{1} \int_{\alpha_{1}^{*}}^{\infty} \alpha d G_{1}(\alpha)}{w^{1-\sigma} L_{1} \int_{\alpha_{1}^{*}}^{\infty} \alpha d G_{1}(\alpha)+\tau^{1-\sigma} L_{2} \int_{\alpha_{2}^{X}}^{\infty} \alpha d G_{2}(\alpha)} \frac{\sigma-1}{\sigma} I_{1} \\
& +\frac{w^{1-\sigma} \tau^{1-\sigma} L_{1} \int_{\alpha_{1}^{X}}^{\infty} \alpha d G_{1}(\alpha)}{L_{2} \int_{\alpha_{2}^{*}}^{\infty} \alpha d G_{2}(\alpha)+w^{1-\sigma} \tau^{1-\sigma} L_{1} \int_{\alpha_{1}^{X}}^{\infty} \alpha d G_{1}(\alpha)} \frac{\sigma-1}{\sigma} I_{2}=L_{1}, \\
L_{2} \int_{\alpha_{2}^{*}}^{\infty} d G_{2}(\alpha) & +\frac{f_{X} L_{2}}{l^{s}} \int_{\alpha_{2}^{X}}^{\infty} d G_{2}(\alpha)+\frac{L_{2} \int_{\alpha_{2}^{*}}^{\infty} \alpha d G_{2}(\alpha)}{L_{2} \int_{\alpha_{2}^{*}}^{\infty} \alpha d G_{2}(\alpha)+w^{1-\sigma} \tau^{1-\sigma} L_{1} \int_{\alpha_{1}^{X}}^{\infty} \alpha d G_{1}(\alpha)} \frac{\sigma-1}{\sigma} I_{2} \\
& +\frac{\tau^{1-\sigma} L_{2} \int_{\alpha_{2}^{X}}^{\infty} \alpha d G_{2}(\alpha)}{w^{1-\sigma} L_{1} \int_{\alpha_{1}^{*}}^{\infty} \alpha d G_{1}(\alpha)+\tau^{1-\sigma} L_{2} \int_{\alpha_{2}^{X}}^{\infty} \alpha d G_{2}(\alpha)} \frac{\sigma}{\sigma} I_{1}=L_{2},
\end{aligned}
$$


for countries 1 and 2, respectively.

We have 7 equations, (16)-(22), and 7 unknowns $\left(\alpha_{1}^{*}, \alpha_{1}^{X}, \alpha_{2}^{*}, \alpha_{2}^{X}, w, I_{1}, I_{2}\right)$. Naturally, it is rather difficult to analytically solve this simultaneous equation system. Thus, we conduct some numerical simulations to derive the effects of international trade on income inequality when the two countries are asymmetric. Throughout the simulations, we select $\tau=1.1$ (when the two countries engage in trade), $\sigma=4, l^{s}=1, f_{X}=1$, and $a_{0}=1$.

\subsection{Different Population}

We first consider the case in which the two countries are different only in the population size. We assume that country 1 is larger than country 2: $L_{1}=100$ and $L_{2}=70$. The ability distributions are the same between the two countries: $k_{1}=k_{2}=2$.

Figure 6 illustrates the simulation result on the impact of international trade on real wages, measured by the indirect utility given by (8). The first observation we want to emphasize is that in both countries, only the middle-income class suffers from opening to trade. That is, the main result obtained in the case of symmetric countries remains valid also when the countries are asymmetric in the population size. As for the comparison between the two countries, we first note that in autarky, the real wage is higher in country 1 than in country 2 for any ability $a$. This is because country 1 as the larger country has more firms, each of which produces a variety that is slightly different from others, so that the price index is lower in country 1 . With fixed and variable trade costs, this advantage of living in the larger country remains even after opening to trade so that the real wage is still higher in country 1 than in country 2 for any ability level.

In addition, income inequality worsens in the smaller country 2 as a consequence of international trade. As Figure 6 indicates, $\alpha_{1}^{*}=\alpha_{2}^{*}$ in autarky, but $\alpha_{1}^{*}<\alpha_{2}^{*}$ and $\alpha_{1}^{X}>\alpha_{2}^{X}$ in the trade equilibrium. Since country 1 has more firms for each quality level, the export cutoff quality must be higher in country 1 than in country 2, i.e., $\alpha_{1}^{X}>\alpha_{2}^{X}$, because otherwise country 2's market would become more competitive than country 1's and hence country 1's export-cutoff firm with $\alpha_{1}^{X}$ would earn less operating profits than $f_{X}$ if country 2's export- 
cutoff firm with $\alpha_{2}^{X}$ earns $f_{X}$ (as it does in equilibrium). But this directly implies that $\alpha_{1}^{*}<\alpha_{2}^{*}$ (since $\alpha_{i}^{X}=\left(\tau^{\sigma-1} f_{X} / l^{s}\right) \alpha_{j}^{*}$, where $i \neq j$ holds) so that country 2's firm that produces a good of quality as low as $\alpha_{2}^{X}$ can sell profitably in country $1 .{ }^{2}$ These relative cutoff points indicate that the proportions of both lowest and highest income groups are larger in country 2 than in country 1 . So we infer that country 2's income inequality worsens compared with country 1's. Figure 7 shows the shifts of the two countries' Lorenz curves as a result of opening to trade. For both countries, the Lorenz curve shifts up for lower percentiles while it shifts down for upper percentiles, mainly reflecting a drop of income for the middleincome class. But country 2's Lorenz curve shifts down relatively more than country 1's. Indeed, the Gini coefficient increases from 0.1148 to 0.1160 in country the smaller country 2 , while it stays the same at 0.1148 in the larger country 1.

\subsection{Different Ability Distributions}

We turn to the case where the two countries are different only in the ability distribution. We assume that $k_{1}=2$ and $k_{2}=4$ : country 1 has relatively more workers with high abilities than country 2. We assume that the two countries have the same population: $L_{1}=L_{2}=100$.

Figure 8 illustrates the simulation result on the impact of international trade on real wages. As in the previous case, only the middle-income class suffers from trade in both countries. We also observe that the real wage for production workers is greater in the talentabundant country 1 than in country 2 regardless of whether the two countries engage in trade. This is because country 1 has more firms that produce goods of high quality than country 2 so that demands for production workers are higher. But real wages for knowledge workers are higher in the talent-scarce country 2 reflecting the scarcity of talent; the wage rate for production workers is higher in country 2 than in country 1 so that the firms in country 2 earn more operating profits than their counterpart in country 1.

Figure 9 shows the shifts of the Lorenz curves as a result of trade. The figure clearly shows

\footnotetext{
${ }^{2}$ It follows from equations (17)-(20) that $\alpha_{1}^{X}=\frac{\tau^{\sigma-1} f_{X}}{w l^{s}} \alpha_{1}^{*}$ and $\alpha_{2}^{X}=\frac{\tau^{\sigma-1} f_{X}}{l^{s}} \alpha_{2}^{*}$ and hence $\alpha_{1}^{*} / w>\alpha_{2}^{*}$. But in this asymmetric-country model, we have $w>1$, which is known as the home market effect (Krugman, 1980, 1991), so that $\alpha_{1}^{*}>\alpha_{2}^{*}$.
} 
that income inequality lessens in country 1 while it worsens in country 2 as a result of opening to trade. Indeed, the Gini coefficient drops from 0.1148 to 0.0979 in the talent-abundant country 1 , while it rises from 0.0567 to 0.0588 in the talent-scarce country 2. Note, however, that income inequality is still higher in the talent-abundant country 1 than the talent-scarce country 2 as these figures of the Gini coefficients show. As Figure 10 indicates, the Lorenz curve of country 1 is still located below that of country 2 in the trade equilibrium even though the gap is narrowed by trade.

\section{Conclusion}

We have built a two-country trade model in which the average ability of knowledge workers hired in a firm determines the quality of the product that the firm produces, in order to examine the impact of international trade on income inequality across workers with different abilities. Knowledge workers are assortatively allocated across firms in equilibrium, which entails firm heterogeneity in terms of product quality. We find that international trade will benefit the firms that produce the highest qualities, while trade decreases the profits for those that barely export their products and those that serve only their individual domestic markets. Consequently, income inequality within knowledge workers, who earn higher income than production workers, expands. International trade increases the real wages for top income earners while decreases those for the middle-income class. The real wages for those in the low-income class who work as production workers increase thanks to the reduced price index as a result of increased varieties of products consumed.

In the basic model, we focus on a single dimensional ability (or talent). In reality, however, there is a variety of abilities-the mathematical ability and artistic ability for example-and workers' abilities in these different dimensions are not perfectly correlated. In the presence of multiple dimensional abilities, globalization can affect different workers differently. Trade liberalization raises the relative price for the export good. If a worker has a great talent that is valued highly in the comparative disadvantage sector, she is likely to be hired in the comparative disadvantage sector and receive relatively high wages. But trade liberalization 
reduces her wages, while she would obtain much higher wages if she migrate to the foreign country that has a comparative advantage in that sector. Thus, globalization can change industrial structure significantly, and affect workers quite differently based on their ability profiles. 


\section{Appendix}

Proof of Proposition 3. First, we show that international trade makes the production workers better off by showing that the product quality index increases (or equivalently, the price index drops) by trade. Then, we show that trade also makes top income earners better off. Finally, we derive the condition under which there exist workers with intermediate abilities such that their real wages fall as a result of opening to trade.

To calculate the utility in autarky, expressed by (8), and its counterpart in the trade equilibrium, we first derive the product quality indices as

$$
\int_{\alpha_{A}^{*}}^{\infty} \alpha f(\alpha) d \alpha=\frac{k \alpha_{0}^{k} L}{l^{s}} \int_{\alpha_{A}^{*}}^{\infty} \alpha^{-k} d \alpha=\frac{k \alpha_{0}^{k} L}{(k-1) l^{s}\left(\alpha_{A}^{*}\right)^{k-1}}
$$

for autarky, and

$$
\int_{\alpha_{T}^{*}}^{\infty} \alpha f(\alpha) d \alpha+\tau^{1-\sigma} \int_{\frac{\tau^{\sigma-1} l_{f} X}{l^{s}} \alpha_{T}^{*}}^{\infty} \alpha f(\alpha) d \alpha=\frac{k \alpha_{0}^{k} L}{(k-1) l^{s}\left(\alpha_{T}^{*}\right)^{k-1}}\left[1+\tau^{k(1-\sigma)}\left(\frac{l^{s}}{f^{X}}\right)^{k-1}\right]
$$

in the trade equilibrium.

Now, we solve the autarkic FE and LM equations, (6) and (7), for $\alpha_{A}^{*}$ and $I_{A}$. Substituting the expression of (23) into (6), we obtain the aggregate income in autarky as

$$
I_{A}=\frac{\sigma l^{s}}{\alpha_{A}^{*}} \times \frac{k \alpha_{0}^{k} L}{(k-1) l^{s}\left(\alpha_{A}^{*}\right)^{k-1}}=\frac{\sigma k L}{k-1}\left(\frac{\alpha_{0}}{\alpha_{A}^{*}}\right)^{k} .
$$

Then, we substitute (25) into (7) to obtain

$$
L=l^{s} \times \frac{L}{l^{s}}\left(\frac{\alpha_{0}}{\alpha_{A}^{*}}\right)^{k}+\left(\frac{\sigma-1}{\sigma}\right) \frac{\sigma k L}{k-1}\left(\frac{\alpha_{0}}{\alpha_{A}^{*}}\right)^{k}=L\left(\frac{\alpha_{0}}{\alpha_{A}^{*}}\right)^{k}\left(\frac{\sigma k-1}{k-1}\right),
$$

which gives us

$$
\alpha_{A}^{*}=\alpha_{0}\left(\frac{\sigma k-1}{k-1}\right)^{\frac{1}{k}} .
$$

Note that $\alpha_{A}^{*}>\alpha_{0}$ holds because $\sigma>1$. We also obtain $I_{A}$ by substituting (27) back to $(25)$ :

$$
I_{A}=\frac{\sigma k L}{k-1} \times \frac{k-1}{\sigma k-1}=\frac{\sigma k L}{\sigma k-1} .
$$


Let us turn to the trade equilibrium. Substituting the expression of (24) into the FE condition (12), we obtain the aggregate income in the trade equilibrium as

$$
I_{T}=\frac{\sigma k L}{k-1}\left(\frac{\alpha_{0}}{\alpha_{T}^{*}}\right)^{k}\left[1+\tau^{k(1-\sigma)}\left(\frac{l^{s}}{f^{X}}\right)^{k-1}\right] .
$$

Then, we substitute (29) into the LM condition (13) to obtain

$$
\begin{aligned}
L= & l^{s} \times \frac{L}{l^{s}}\left(\frac{\alpha_{0}}{\alpha_{T}^{*}}\right)^{k}+f^{X} \times \frac{L}{l^{s}}\left(\frac{\alpha_{0}}{\alpha_{T}^{*}}\right)^{k}\left(\frac{l^{s}}{\tau^{\sigma-1} f^{X}}\right)^{k} \\
& +\left(\frac{\sigma-1}{\sigma}\right) \frac{\sigma k L}{k-1}\left(\frac{\alpha_{0}}{\alpha_{T}^{*}}\right)^{k}\left[1+\tau^{k(1-\sigma)}\left(\frac{l^{s}}{f^{X}}\right)^{k-1}\right] \\
= & L\left(\frac{\alpha_{0}}{\alpha_{T}^{*}}\right)^{k}\left[1+\tau^{k(1-\sigma)}\left(\frac{l^{s}}{f^{X}}\right)^{k-1}\right]\left(\frac{\sigma k-1}{k-1}\right) .
\end{aligned}
$$

Thus, we have

$$
\alpha_{T}^{*}=\alpha_{0}\left[1+\tau^{k(1-\sigma)}\left(\frac{l^{s}}{f^{X}}\right)^{k-1}\right]^{\frac{1}{k}}\left(\frac{\sigma k-1}{k-1}\right)^{\frac{1}{k}} .
$$

Substituting (30) back to (29), we obtain

$$
\begin{aligned}
I_{T} & =\frac{\sigma k L}{k-1} \times \frac{k-1}{\sigma k-1} \times\left[1+\tau^{k(1-\sigma)}\left(\frac{l^{s}}{f^{X}}\right)^{k-1}\right]^{-1} \times\left[1+\tau^{k(1-\sigma)}\left(\frac{l^{s}}{f^{X}}\right)^{k-1}\right] \\
& =\frac{\sigma k L}{\sigma k-1} .
\end{aligned}
$$

It is immediate from $(28)$ and $(31)$ that $I_{A}=I_{T}$.

Since the production worker's wage is normalized to 1, it is obvious from (8) and (14) that the production workers are better off by opening to trade if and only if the quality index increases by trade, i.e.,

$$
\int_{\alpha_{T}^{*}}^{\infty} \alpha f(\alpha) d \alpha+\tau^{1-\sigma} \int_{\frac{\tau^{\sigma-1} f}{l^{s}} \alpha_{T}^{*}}^{\infty} \alpha f(\alpha) d \alpha>\int_{\alpha_{A}^{*}}^{\infty} \alpha f(\alpha) d \alpha .
$$

Now, it follows from (23) and (27) that

$$
\int_{\alpha_{A}^{*}}^{\infty} \alpha f(\alpha) d \alpha=\frac{k L \alpha_{0}^{k}}{(k-1) l^{s} \alpha_{0}^{k-1}\left(\frac{\sigma k-1}{k-1}\right)^{\frac{k-1}{k}}} .
$$


Similarly, we obtain from (24) and (30) that

$$
\begin{aligned}
& \int_{\alpha_{T}^{*}}^{\infty} \alpha f(\alpha) d \alpha+\tau^{1-\sigma} \int_{\frac{\tau^{\sigma-1} f_{f} X}{l^{s}} \alpha_{T}^{*}}^{\infty} \alpha f(\alpha) d \alpha \\
& =\frac{k \alpha_{0}^{k} L}{(k-1) l^{s} \alpha_{0}^{k-1}\left(\frac{\sigma k-1}{k-1}\right)^{\frac{k-1}{k}}}\left[1+\tau^{k(1-\sigma)}\left(\frac{l^{s}}{f^{X}}\right)^{k-1}\right]^{\frac{1}{k}} .
\end{aligned}
$$

The direct comparison between (33) and (34) reveals that (32) holds, and hence the production workers are better off by international trade.

Next, we show that the highest income earners are better off by opening to trade. As Figure 5 suggests, we need only show that $u_{T}^{\prime}(a)>u_{A}^{\prime}(a)$ for $a>\alpha^{X}$. Since $w_{A}(a)=\tilde{\pi}(a) / l^{s}$ for $a \geq \alpha_{A}^{*}$, where $\tilde{\pi}$ is defined by $(5)$, and $w_{T}(a)=\left[\tilde{\pi}_{d}(a)+\tilde{\pi}_{X}(a)-f_{X}\right] / l^{s}$ for $a \geq \alpha^{X}$, we obtain from (5), (8), (9), (10), and (14) that

$$
\begin{aligned}
& u_{A}(a)=\frac{(\sigma-1) a I_{A}}{\sigma^{2} l^{s}\left[\int_{\alpha_{A}^{*}}^{\infty} \alpha f(\alpha) d \alpha\right]^{\frac{\sigma-2}{\sigma-1}}}, \text { for } a \geq \alpha_{A}^{*}, \\
& u_{T}(a)=\frac{(\sigma-1) a\left(1+\tau^{1-\sigma}\right) I_{T}}{\sigma^{2} l^{s}\left[\int_{\alpha_{T}^{*}}^{\infty} \alpha f(\alpha) d \alpha+\tau^{1-\sigma} \int_{\alpha^{X}}^{\infty} \alpha f(\alpha) d \alpha\right]^{\frac{\sigma-2}{\sigma-1}}}, \text { for } a \geq \alpha^{X} .
\end{aligned}
$$

Note that in both autarky and trade, an individual's utility is higher, the higher is the product quality index, if and only if $1<\sigma<2$. The higher the quality index, a knowledge worker is better off as a consumer, but worse off as a residual claimer of a firm that competes with other firms. The former effect outweighs the latter if and only if $\sigma<2$, i.e., the elasticity of substitution is small enough that the negative impact of an increase in the quality index through a drop of the firm's operating profits is sufficiently small.

Now, comparing (35) and (36), we have $u_{T}(a)>u_{A}(a)$ if and only if

$$
\left(1+\tau^{1-\sigma}\right)>\left[\frac{\int_{\alpha_{T}^{*}}^{\infty} \alpha f(\alpha) d \alpha+\tau^{1-\sigma} \int_{\alpha^{X}}^{\infty} \alpha f(\alpha) d \alpha}{\int_{\alpha_{A}^{*}}^{\infty} \alpha f(\alpha) d \alpha}\right]^{\frac{\sigma-2}{\sigma-1}}
$$

where we have used $I_{A}=I_{T}$. The expression in the square brackets on the right-hand side is greater than 1 as we have shown above. Thus, this inequality is satisfied if $\sigma \leq 2$. To see if this inequality is also satisfied even if $\sigma>2$, we first note that the right-hand side increases with $\sigma$ when $\sigma \geq 2$. So we compare $1+\tau^{1-\sigma}$ with the limit of the right-hand side as $\sigma \rightarrow \infty$. 
In the limit, the inequality can be written as

$$
\int_{\alpha_{A}^{*}}^{\infty} \alpha f(\alpha) d \alpha>\frac{1}{1+\tau^{1-\sigma}} \int_{\alpha_{T}^{*}}^{\infty} \alpha f(\alpha) d \alpha+\frac{\tau^{1-\sigma}}{1+\tau^{1-\sigma}} \int_{\alpha^{X}}^{\infty} \alpha f(\alpha) d \alpha
$$

which is satisfied since $\alpha_{A}^{*}<\alpha_{T}^{*}<\alpha^{X}$. Thus, we have shown that the higher income earners benefit from trade.

Finally, we derive the condition under which the middle-income earners are worse off by trade. In the trade equilibrium, the utility of a knowledge worker with $a \in\left(\alpha_{T}^{*}, \alpha^{X}\right)$ can be written as

$$
u_{T}(a)=\frac{(\sigma-1) a I_{T}}{\sigma^{2} l^{s}\left[\int_{\alpha_{T}^{*}}^{\infty} \alpha f(\alpha) d \alpha+\tau^{1-\sigma} \int_{\alpha^{X}}^{\infty} \alpha f(\alpha) d \alpha\right]^{\frac{\sigma-2}{\sigma-1}}}
$$

Using $I_{A}=I_{T}$, we compare this utility with $u_{A}(a)$, shown in (35), to find that $u_{A}(a)>u_{T}(a)$ for $a \in\left(\alpha_{T}^{*}, \alpha^{X}\right)$ if and only if

$$
\left[\int_{\alpha_{A}^{*}}^{\infty} \alpha f(\alpha) d \alpha\right]^{\frac{\sigma-2}{\sigma-1}}<\left[\int_{\alpha_{T}^{*}}^{\infty} \alpha f(\alpha) d \alpha+\tau^{1-\sigma} \int_{\alpha^{X}}^{\infty} \alpha f(\alpha) d \alpha\right]^{\frac{\sigma-2}{\sigma-1}} .
$$

It follows from (32) that this inequality holds and hence opening to trade makes the middleincome class worse off if and only if $\sigma>2$.

Proof of Proposition 4. It follows directly from (8) and (14) that each country's utilitarian social welfare can be written as

$$
\begin{aligned}
S W_{A} & =\frac{(\sigma-1) I_{A}}{\sigma\left[\int_{\alpha_{A}^{*}}^{\infty} \alpha f(\alpha) d \alpha\right]^{\frac{1}{1-\sigma}}}, \\
S W_{T} & =\frac{(\sigma-1) I_{T}}{\sigma\left[\int_{\alpha_{T}^{*}}^{\infty} \alpha f(\alpha) d \alpha+\tau^{1-\sigma} \int_{\alpha^{X}}^{\infty} \alpha f(\alpha) d \alpha\right]^{\frac{1}{1-\sigma}}} .
\end{aligned}
$$

Thus, trade improves utilitarian social welfare if and only if

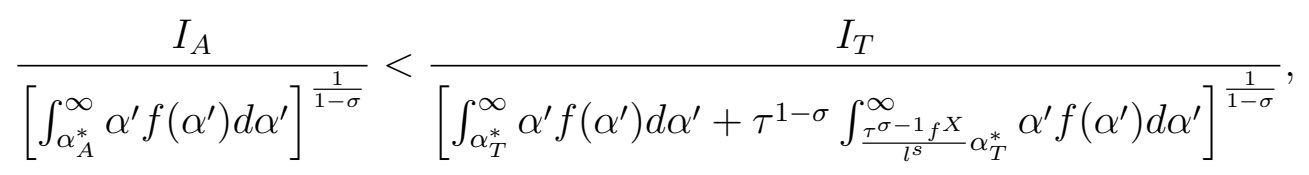

which is satisfied since $I_{A}=I_{T}$, as shown in the proof of Proposition 3, and the product quality index is larger in the trade equilibrium than in autarky, as shown in (32). 
Proof of Proposition 5. Recall that the equilibrium wage schedules in autarky and in trade are given by

$$
w_{A}(\alpha)=\left\{\begin{array}{ccc}
1 & \text { for } & \alpha \in\left[0, \alpha_{A}^{*}\right) \\
\frac{\alpha}{\alpha_{A}^{*}} & \text { for } & \alpha \in\left[\alpha_{A}^{*}, \infty\right)
\end{array}\right.
$$

and

$$
w_{T}(\alpha)=\left\{\begin{array}{ccc}
1 & \text { for } & \alpha \in\left[0, \alpha_{T}^{*}\right) \\
\frac{\alpha}{\alpha_{T}^{*}} & \text { for } & \alpha \in\left[\alpha_{T}^{*}, \alpha^{X}\right) \\
\frac{\alpha}{\alpha_{T}^{*}}+\frac{\left(\alpha-\alpha^{X}\right) f_{X}}{l^{s} \alpha^{X}} & \text { for } & \alpha \in\left[\alpha^{X}, \infty\right),
\end{array}\right.
$$

respectively. It follows from $\alpha_{A}^{*}<\alpha_{T}^{*}<\alpha^{X}$ that there exists $\bar{\alpha}\left(>\alpha^{X}\right)$ such that (i) $w_{T}(\bar{\alpha})=w_{A}(\bar{\alpha})$; (ii) $w_{T}(\alpha) \leq w_{A}(\alpha)$ for all $\alpha \leq \bar{\alpha}$; and (iii) $w_{T}(\alpha)>w_{A}(\alpha)$ for all $\alpha>\bar{\alpha}$, as depicted in Figure 4. This implies that $\mathcal{L}_{A}(a)=\mathcal{L}_{T}(a)$ for all $a \leq \alpha_{A}^{*}$, and $\mathcal{L}_{A}(a)>\mathcal{L}_{T}(a)$ for all $a>\alpha_{A}^{*}$, since $w_{A}(a)=w_{T}(a)=1$ for $a \leq \alpha_{A}^{*}$ and $\int_{0}^{\infty} w_{A}(a) d G(a)=\int_{0}^{\infty} w_{T}(a) d G(a)$, which is shown in the proof of Proposition 3 as $I_{A}=I_{T}$. Thus, the income distribution under international trade is Lorenz-dominated by the one in autarky. 


\section{References}

[1] Acemoglu, Daron and David Autor (2011), "Skills, Tasks and Technologies: Implications for Employment and Earnings," Handbook of Labor Economics 4(B), 1043-1171, Elsevier.

[2] Blanchard, Emily and Gerald Willmann (2011), "Trade, Education, and the Shrinking Middle Class," unpublished manuscript, Dartmouth College.

[3] Caliendo, Lorenzo, and Esteban Rossi-Hansberg (2012), "The Impact of Trade on Organization and Productivity," Quarterly Journal of Economics, 127, 1393-1467.

[4] Costinot, Arnaud and Jonathan Vogel (2010), "Matching and Inequality in the World Economy," Journal of Political Economy, 118, 747-786.

[5] The Economist, January 14th-20th 2012.

[6] Egger, Harmut and Udo Kreickemeier (2012), 'Fairness, Trade, and Inequality,' Journal of International Economics, 86, 184-196.

[7] Helpman, Elhanan, Oleg Itskhoki, Marc-Andreas Muendler, and Stephen Redding (2011), "Trade and Inequality: From Theory to Estimation," unpublished manuscript, Harvard University.

[8] Helpman, Elhanan, Oleg Itskhoki, and Stephen Redding (2010a), "Inequality and Unemployment in a Global Economy," Econometrica, 78, 1239-1283.

[9] Helpman, Elhanan, Oleg Itskhoki, and Stephen Redding (2010b), "Unequal Effects of Trade on Workers with Different Abilities," Journal of European Economic Association, Papers and Proceedings.

[10] Krugman, Paul (1980), "Scale Economies, Product Differentiation, and the Pattern of Trade", American Economic Review, 70, 950-959. 
[11] Krugman, Paul (1991), "Increasing Returns and Economic Geography", Journal of Political Economy, 99, 483-499.

[12] Lucas, R.E. Jr. (1978), "On the Size Distribution of Business Firms," Bell Journal of Economics, 9, 508-523.

[13] Manasse, Paolo and Alessandro Turrini (2001), "Trade, Wages, and 'Superstars'," Journal of International Economics, 54, 97-117.

[14] Melitz, Marc (2003), "The Impact of Trade on Intra-Industry Reallocations and Aggregate Industry Productivity", Econometrica, 71, 1695-1725.

[15] Monte, Ferdinando (2011), "Skill Bias, Trade, and Wage Dispersion," Journal of International Economics, 83, 202-218.

[16] Yeaple, Stephen Ross (2005), "A Simple Model of Firm Heterogeneity, International Trade, and Wages", Journal of International Economics, 65, 1-20. 


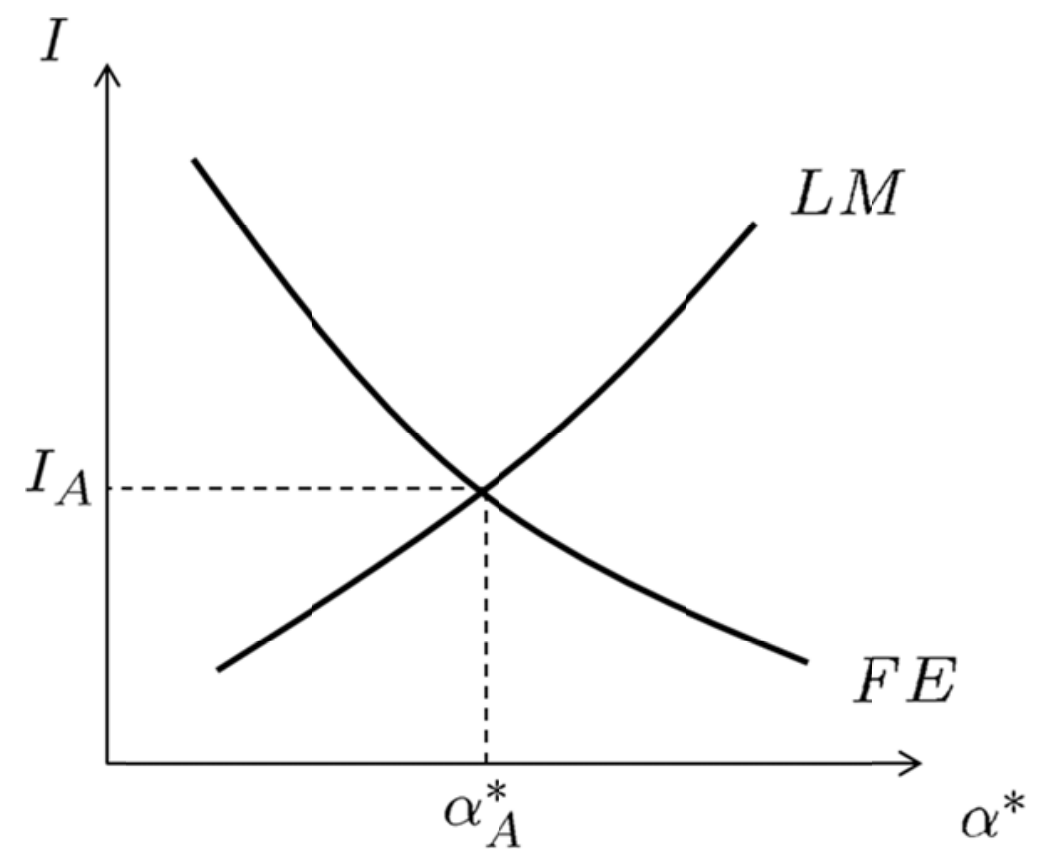

Figure 1. Autarkic equilibrium 


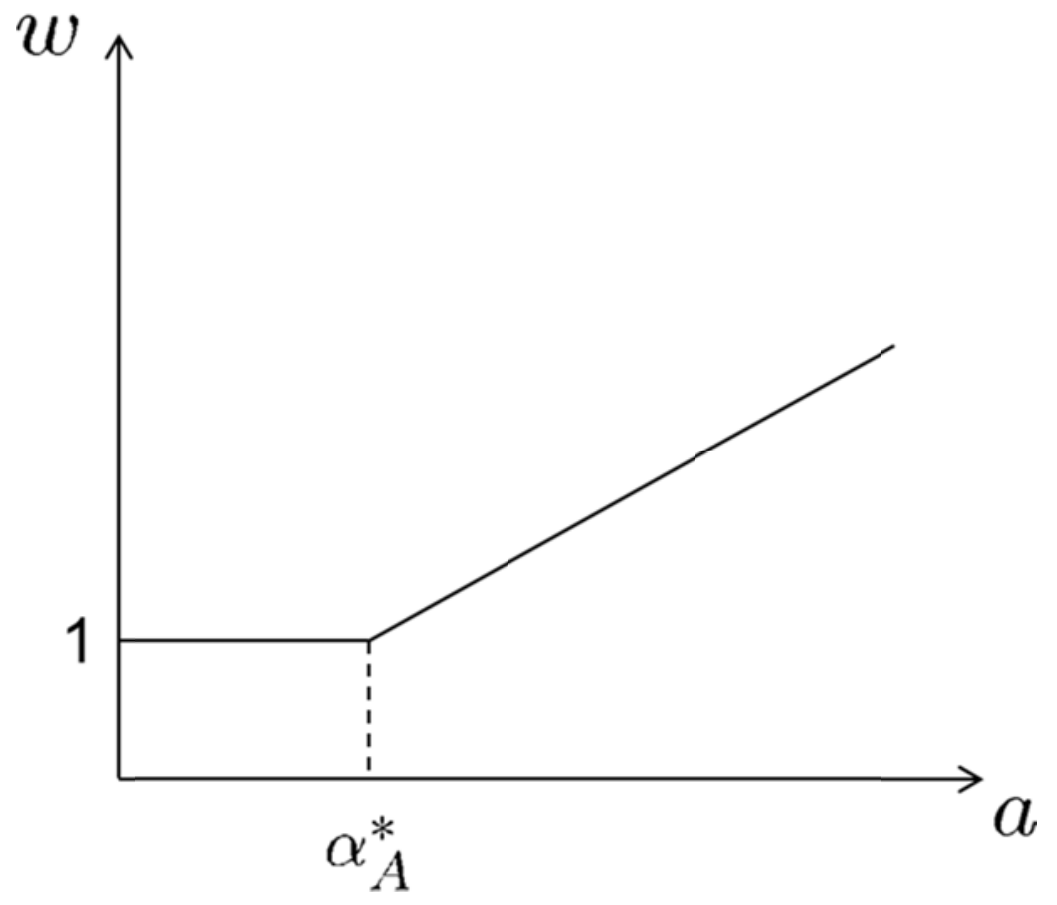

Figure 2. Autarkic equilibrium wage schedule 


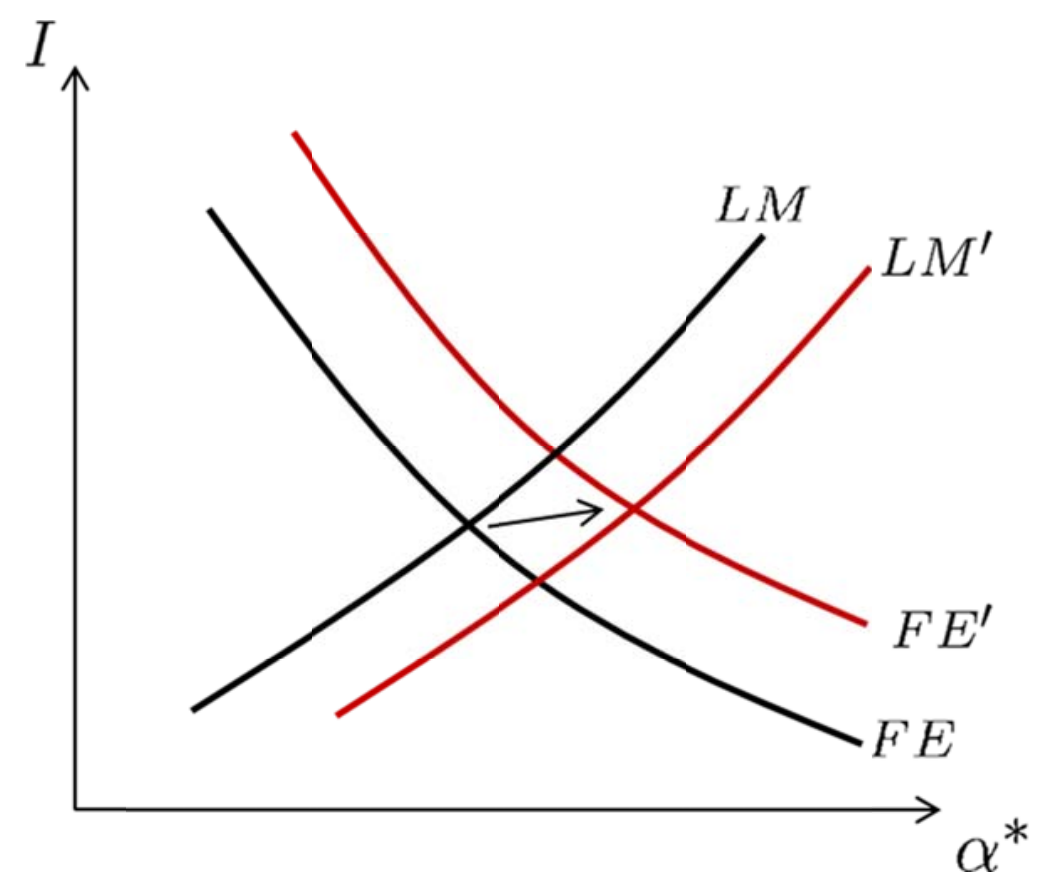

Figure 3. Trade equilibrium 


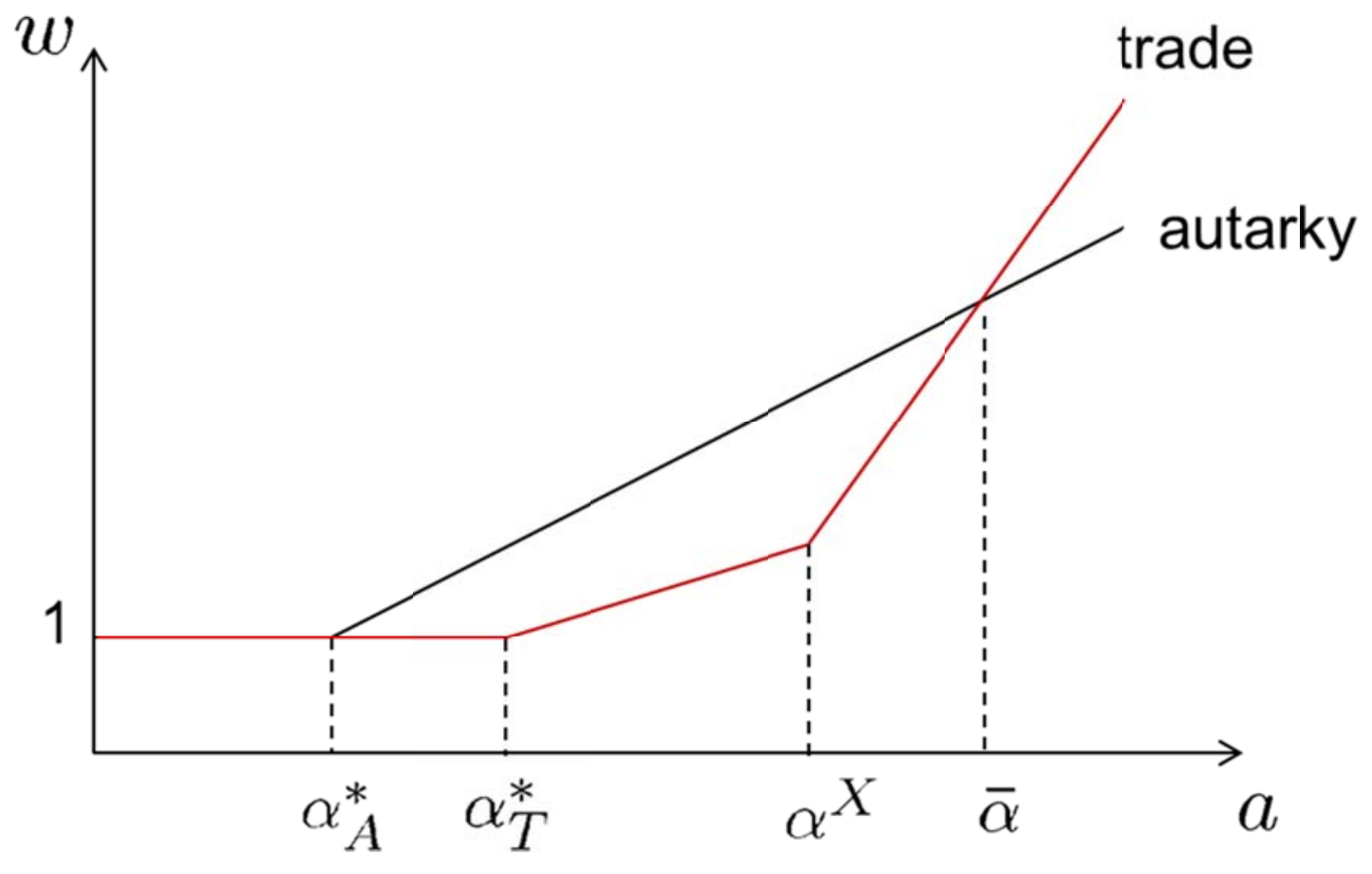

Figure 4. Impact of trade on nominal wages 


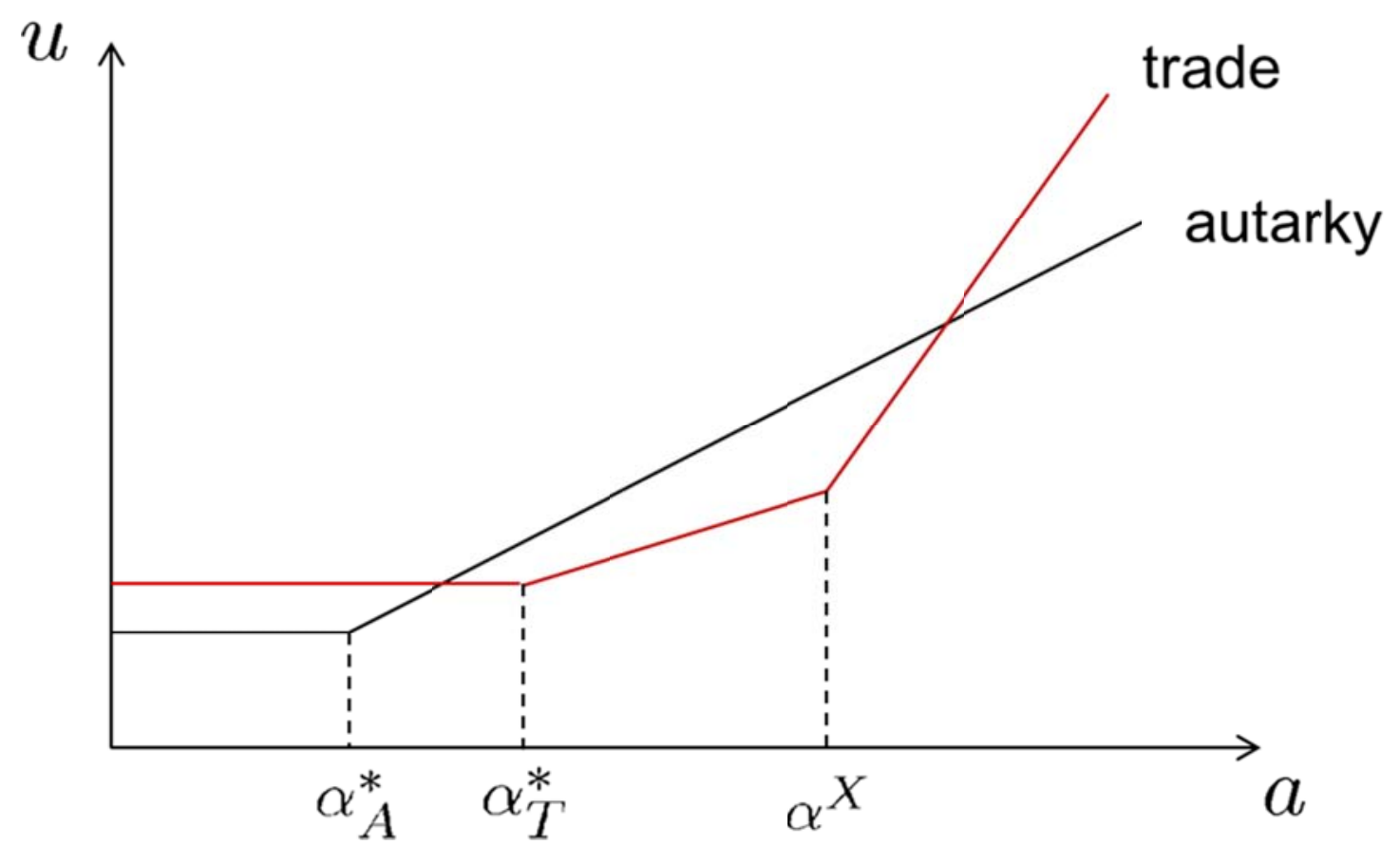

Figure 5. Impact of trade on real wages 
Figure 6. Real wage schedules

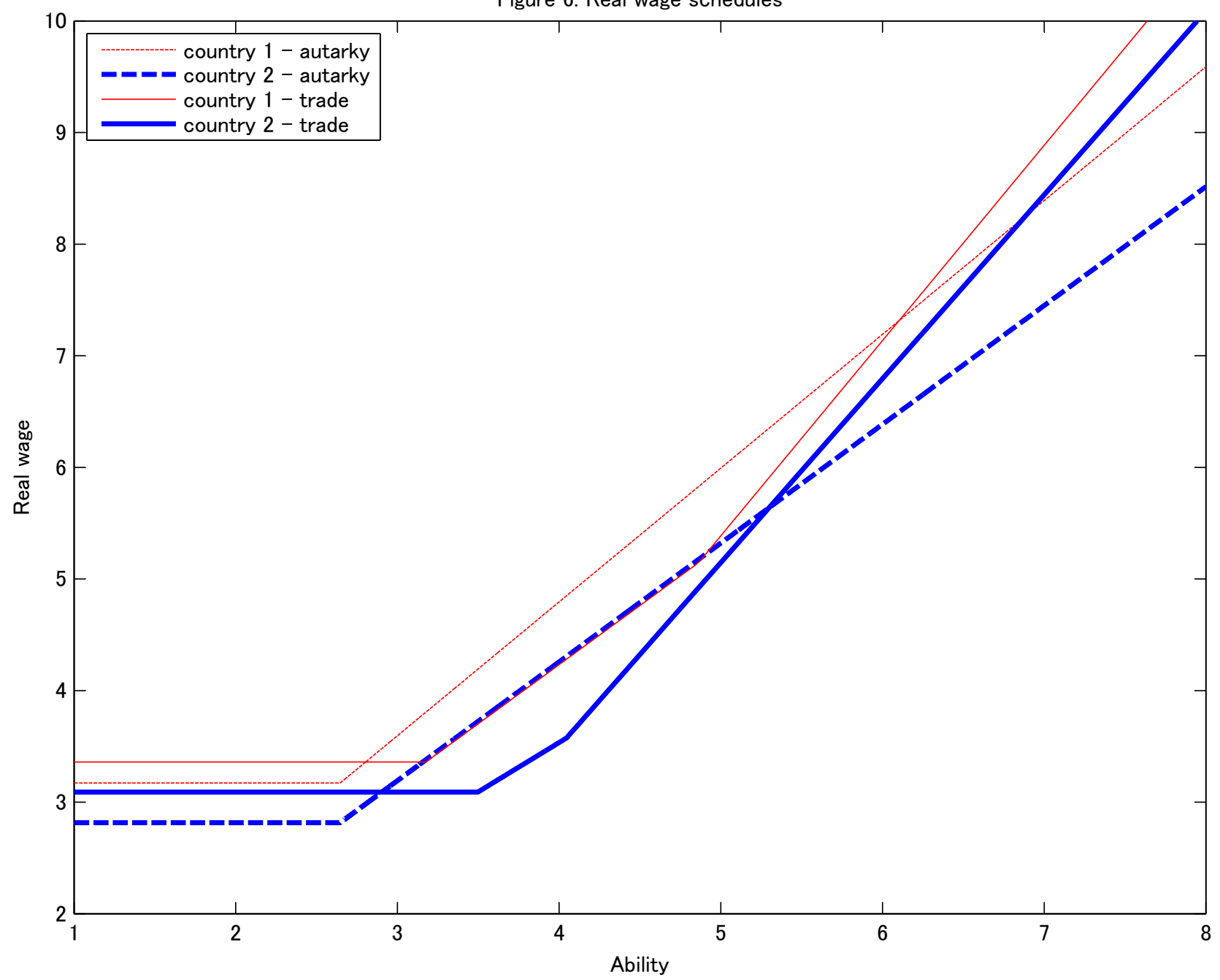




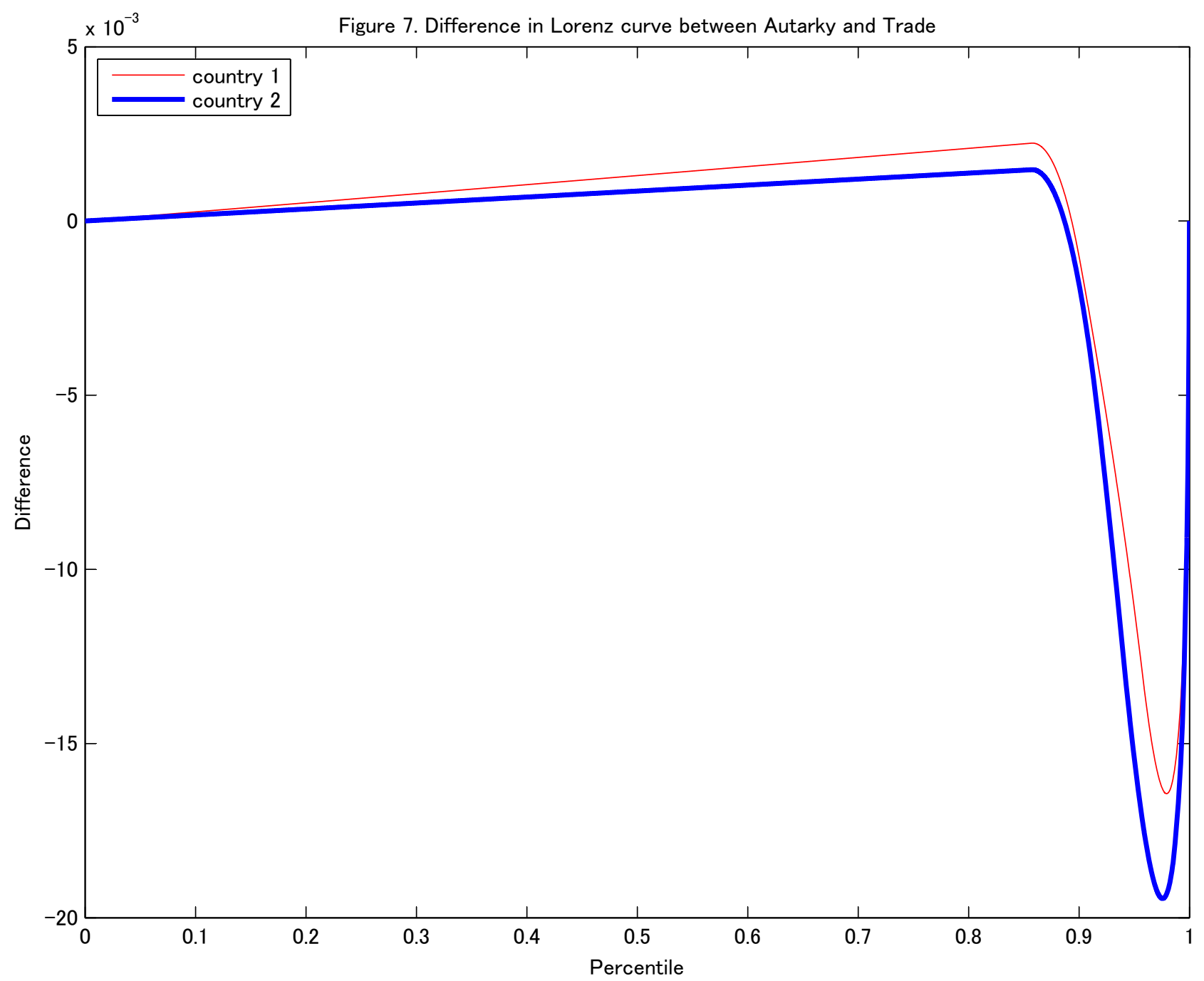


Figure 8. Real wage schedules

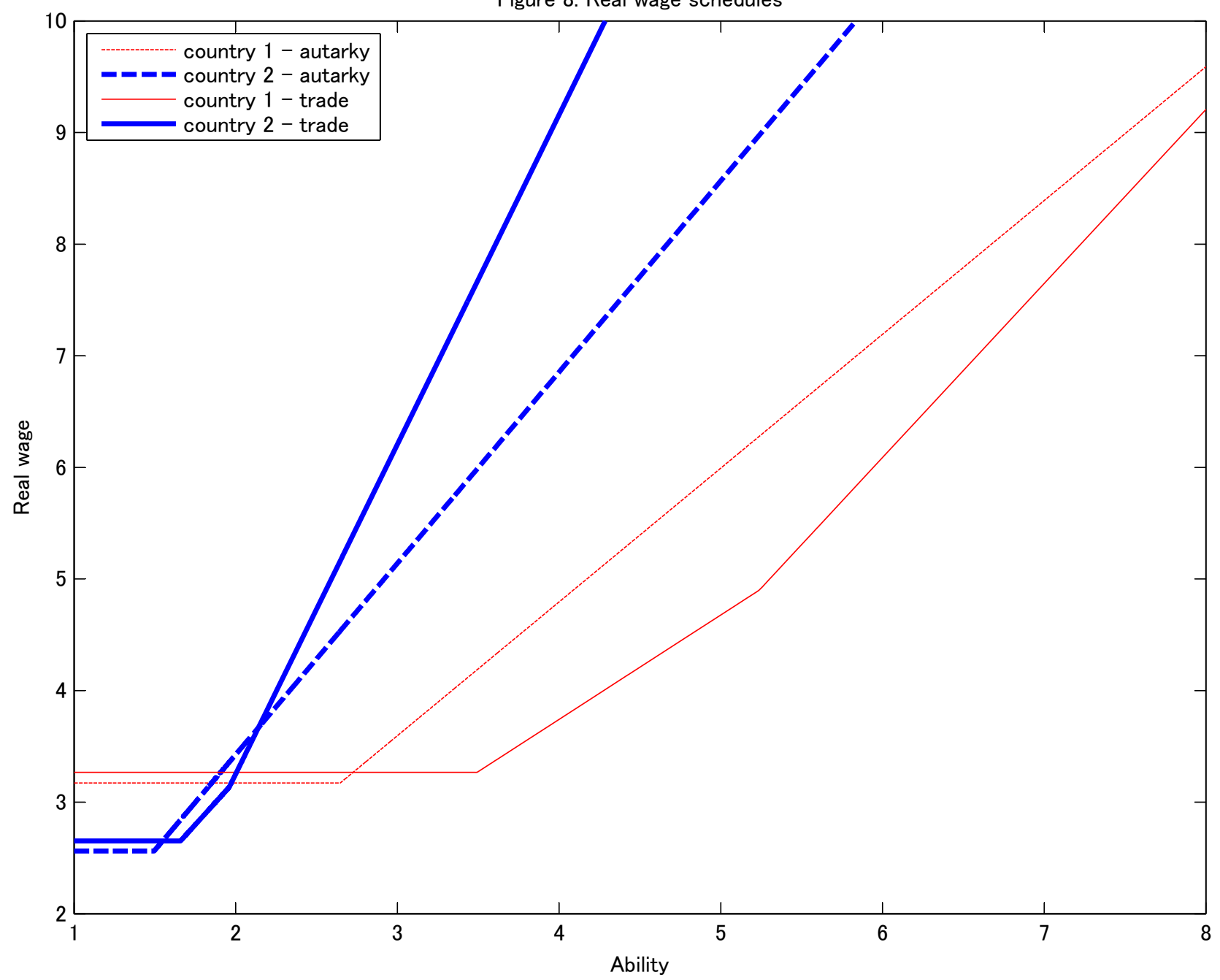




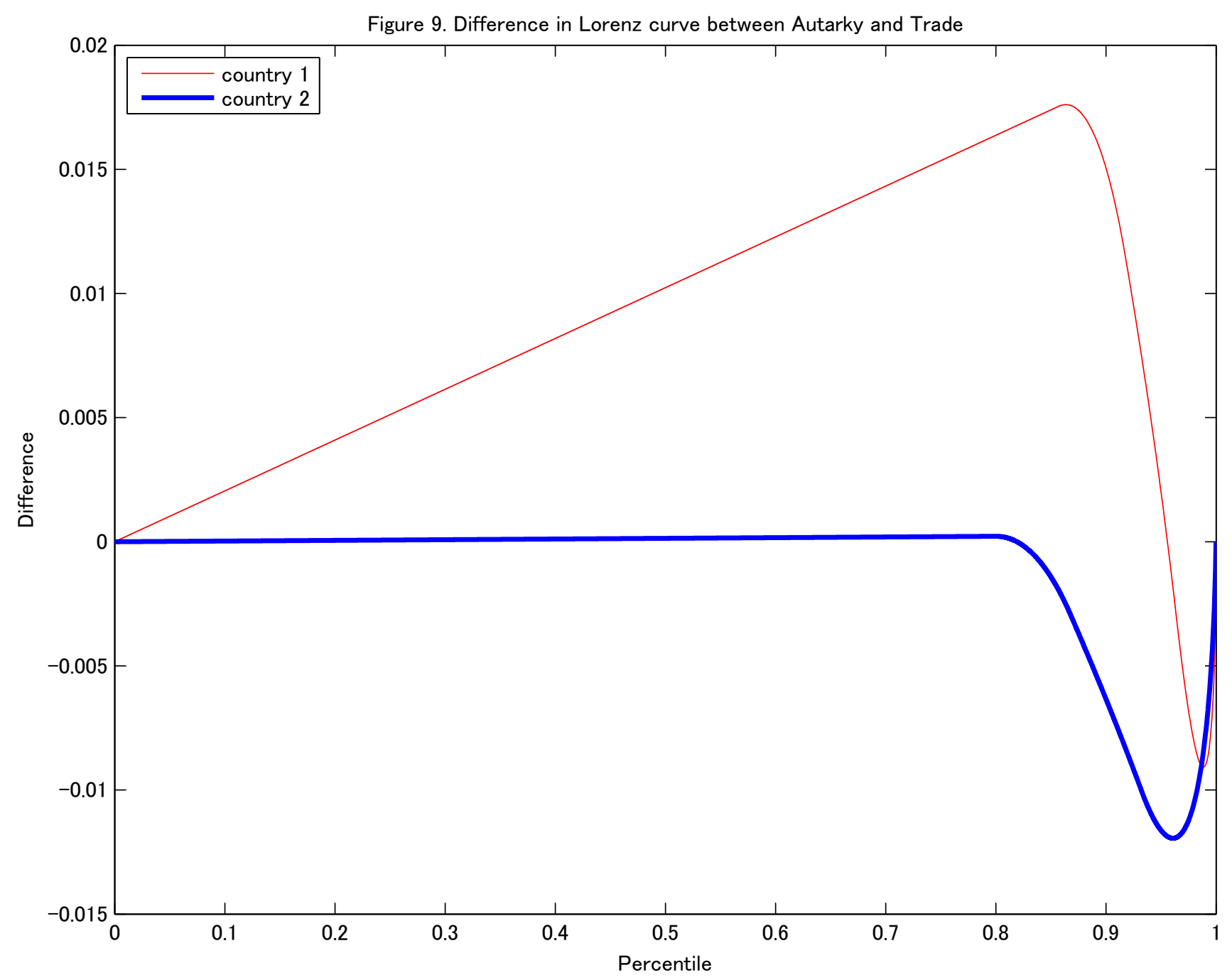


Figure 10. Lorenz curve in Trade

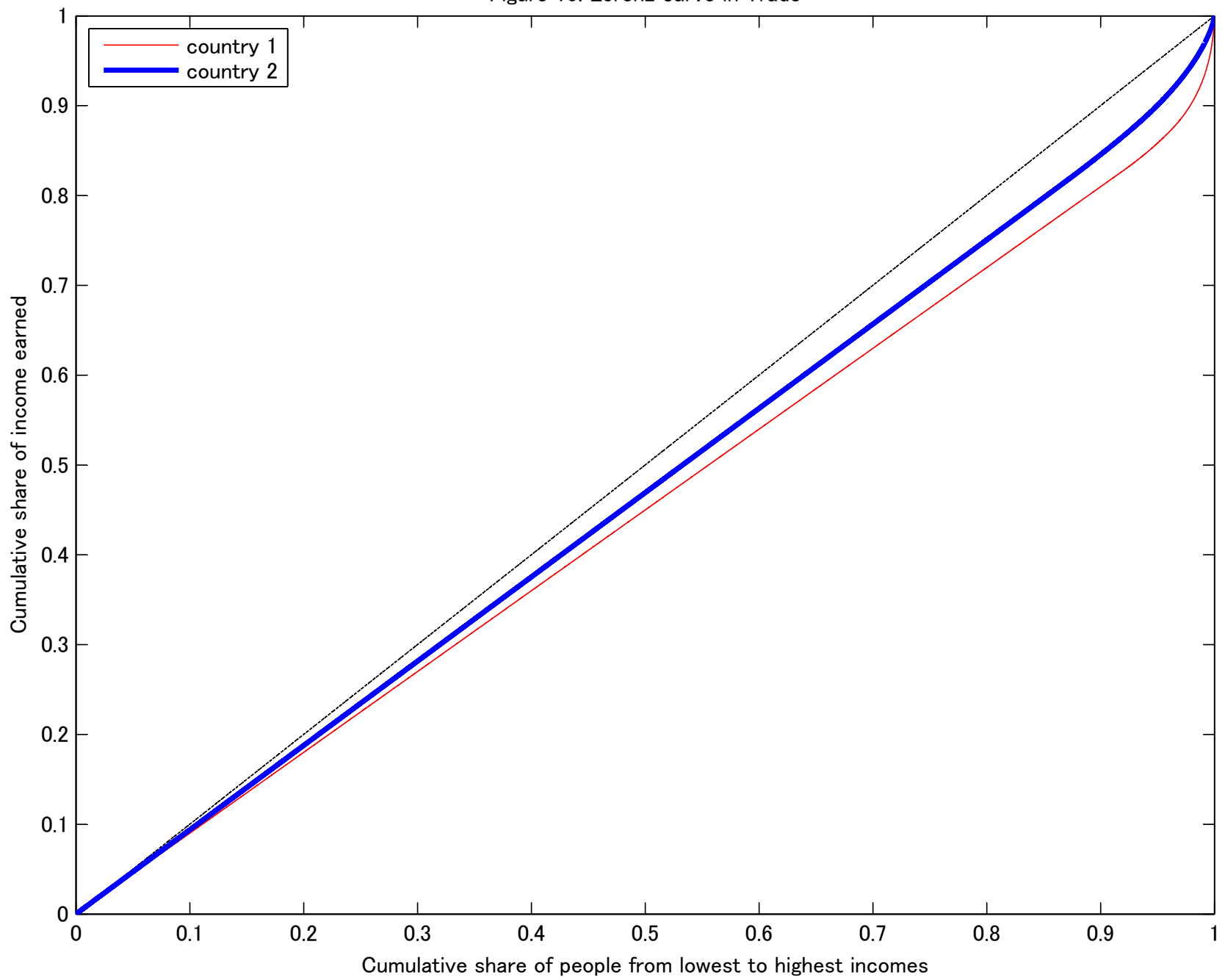

